\section{Commentary: Transit time flow measurements for coronary artery bypass graft: Go with the flow}

\author{
Sigrid E. Sandner, MD, ${ }^{a}$ and \\ Mario F. L. Gaudino, MD ${ }^{\mathrm{b}}$
}

On March 25, 2019, British Airways flight BA3271, which departed from London's City Airport bound for Düsseldorf, Germany, instead mistakenly landed in Edinburgh, Scotland. An analysis of US flights looking at journeys from the early 1990s until 2014 found more than 150 incidents where aircraft had landed in the wrong place. Many such incidents have happened when pilots rely on sight rather than software and navigation tools. In light of the checks and safeguards in place in aviation, who would consider it appropriate to submit patients to complex surgical procedure (as in the case of coronary revascularization) without using specific tools to confirm that patients have effectively reached their destination (ie, adequately functioning grafts)?

Quality assurance in coronary surgery has evolved over the past decade to include intraoperative performance measures, with the underlying premise that intraoperative evaluation of quality would lead to improved patient outcomes. Several methods for intraoperative quality assessment exist that are limited in part by practical applicability. Among these, transit time flow measurement (TTFM) is currently the most frequently used. However, TTFM is employed in only approximately $20 \%$ of coronary revascularization procedures in the United States. ${ }^{1}$ Reluctance to widespread adoption of TTFM is most likely due to the fact that

\footnotetext{
From the ${ }^{\mathrm{a}}$ Department of Cardiac Surgery, Medical University of Vienna, Vienna, Austria; and ${ }^{\mathrm{b}}$ Department of Cardiothoracic Surgery, Weill Cornell Medicine, New York Presbyterian Hospital, New York, NY.

Disclosures: The authors reported no conflicts of interest.

The Journal policy requires editors and reviewers to disclose conflicts of interest and to decline handling or reviewing manuscripts for which they may have a conflict of interest. The editors and reviewers of this article have no conflicts of interest.

Received for publication Dec 1, 2020; revisions received Dec 1, 2020; accepted for publication Dec 18, 2020; available ahead of print Dec 26, 2020.

Address for reprints: Mario F. L. Gaudino, MD, Department of Cardiothoracic Surgery, Weill Cornell Medicine, New York Presbyterian Hospital, 525 E 68th St, New York, NY 10065 (E-mail: mfg9004@med.cornell.edu).

JTCVS Techniques 2021;7:144-5

2666-2507

Copyright (c) 2020 The Authors. Published by Elsevier Inc. on behalf of The American Association for Thoracic Surgery. This is an open access article under the CC BY-NCND license (http://creativecommons.org/licenses/by-nc-nd/4.0/).

https://doi.org/10.1016/j.xjtc.2020.12.035
}

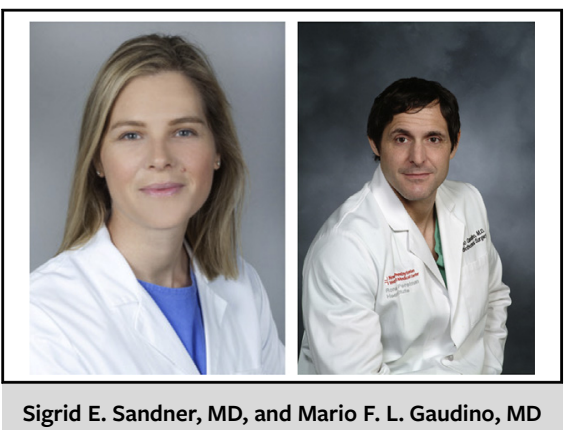

CENTRAL MESSAGE

Intraoperative quality assurance using transit time flow measurement is an important part of coronary surgery.

available evidence on the predictive ability of TTFM for clinical outcomes has yielded conflicting results. Most recently, a systematic review and meta-analysis of mainly observational studies that included 8943 patients undergoing coronary artery bypass graft procedure and 15,673 grafts reported that $4.3 \%$ of patients and $2.0 \%$ of grafts required revision. TTFM measurements correlated with graft patency during short-to midterm follow-up. ${ }^{2}$ The only randomized trial to date comparing TTFM with no perioperative imaging did not show a difference in the rate of graft occlusion on coronary angiography or major adverse cardiac events at 1 year; however, no sample size calculation was performed for this trial and findings can be considered exploratory only. ${ }^{3}$ In addition, standardization of performing TTFM and interpretation of measurements are essential to increase use.

Akhrass and colleagues ${ }^{4}$ review available methods for intraoperative graft assessment, with a focus on TTFM. Arguably the great limitation to TTFM is that there is no 1-size-fits-all algorithm for decision making. A multitude of patient-related and situative factors influence graft flow, and all need to be equally considered when interpreting TTFM measurements. The cutoff values indicating acceptable graft function given by Akhrass and colleagues ${ }^{4}$ represent the currently available best evidence and have been associated with graft patency. They may be considered a framework of objective criteria, but in the last consequence, their interpretation is at least in part subjective, and decision making is based on surgeon experience. As such, the authors are commended for providing a hands-on approach in outlining operative scenarios to aid in interpretation of 
findings of impaired graft flow such as competitive flow, steal phenomena, or spasm.

Arterial grafts are more susceptible to injury during harvesting, and more susceptible to competitive flow. Thus, arterial grafts are most likely to benefit from intraoperative assessment. The diagnostic accuracy and predictive ability of TTFM appears strongest for arterial grafts. ${ }^{5}$ In the majority of observational studies a direct correlation between mean graft flow and internal thoracic artery patency could be observed, with a threshold of $>20 \mathrm{~mL} / \mathrm{min}$ indicating an acceptable graft. Similarly, a pulsatility index $>5$ was significantly associated with occurrence of major adverse cardiac events and mortality in an analysis of nearly 1000 arterial grafts. $^{6}$

Surgeons-especially those who specialize in cardiothoracic surgeries-must aim for refinement of technique, and this includes multiple arterial grafting as well as intraoperative quality assurance. Building experience is key, particularly for TTFM, and routine use is strongly encouraged.
Here we are in 2021, and visual flight alone does not seem the best way to take our patients to the right destination.

\section{References}

1. Ohmes LB, Di Franco A, Di Giammarco G, Rosati CM, Lau C, Girardi LN, et al. Techniques for intraoperative graft assessment in coronary artery bypass surgery. $J$ Thorac Dis. 2017;9(Suppl 4):S327-32.

2. Thuijs D, Bekker MWA, Taggart DP, Kappetein AP, Kieser TM, Wendt D, et al Improving coronary artery bypass grafting: a systematic review and metaanalysis on the impact of adopting transit-time flow measurement. Eur J Cardiothorac Surg. 2019;56:654-63.

3. Singh SK, Desai ND, Chikazawa G, Tsuneyoshi H, Vincent J, Zagorski BM, et al. The graft imaging to improve patency (GRIIP) clinical trial results. J Thorac Cardiovasc Surg. 2010;139:294-301.e1.

4. Akhrass R, Bakaeen FG. Intraoperative graft patency validation: friend or foe? J Thorac Cardiovasc Surg Tech. 2021;7:131-7.

5. Niclauss L. Techniques and standards in intraoperative graft verification by transit time flow measurement after coronary artery bypass graft surgery: a critical review. Eur J Cardiothorac Surg. 2017;51:26-33.

6. Kieser TM, Rose S, Kowalewski R, Belenkie I. Transit-time flow predicts outcomes in coronary artery bypass graft patients: a series of 1000 consecutive arteria grafts. Eur J Cardiothorac Surg. 2010;38:155-62. 